\title{
Role of mechanical factors in the evaluation of pedicle screw type spinal fixation devices
}

\author{
V. K. Goel, N. A. Ebraheim, A. Biyani, S. Rengachary', A. Faizan \\ Department of Bioengineering and Orthopedics, University of Toledo and Medical College of Ohio, Toledo, OH, ${ }^{1}$ Department of \\ Neurosurgery, Wayne Sate University, Detroit, MI, USA
}

Prior to implantation, spinal implants are subjected to rigorous testing to ensure safety and efficacy. A full battery of tests for the devices may include many steps ranging from biocompatibility tests to in vivo animal studies. This paper describes some of the essential tests from a mechanical engineering perspective (e.g., motion, load sharing, bench type tests, and finite element model analyses). These protocols reflect the research experience of the past decade or so.

Key words: Instrumentation, biomechanics, pull out strength, stability

\section{Introduction}

Human ligamentous spine is a complex structure consisting of vertebrae, interposing discs, and ligaments (Figure 1). For example, five vertebrae and their supporting soft tissue structures constitute the lumbar region of the spine. Each lumbar vertebra consists of a body and a posterior vertebral arch. The posterior bony elements include the pedicles, facets, laminae, transverse processes, and spinous process. The ligaments assist in holding the vertebra together. The vertebral disc interposed in between the two vereberal bodies is made up of the nucleus pulposus, the annulus, and the two cartilaginous end plates. In a normal person, these spinal structures along with the muscles spanning the spine function in unison to provide trunk flexibility, support of the upper body weight, and protection of the spinal cord and nerve roots that pass through the spinal canal and foramen. Spinal components that are in abnormal state, be it of neoplasmic origin, trauma, etc., can compromise the quality of life. Surgical interventions may become essential in some cases. The basic principle underlying surgery is to either dissect or remove the impinging or mal-functioning structures. However, depending upon the amount of bony and soft tissue decompression achieved,

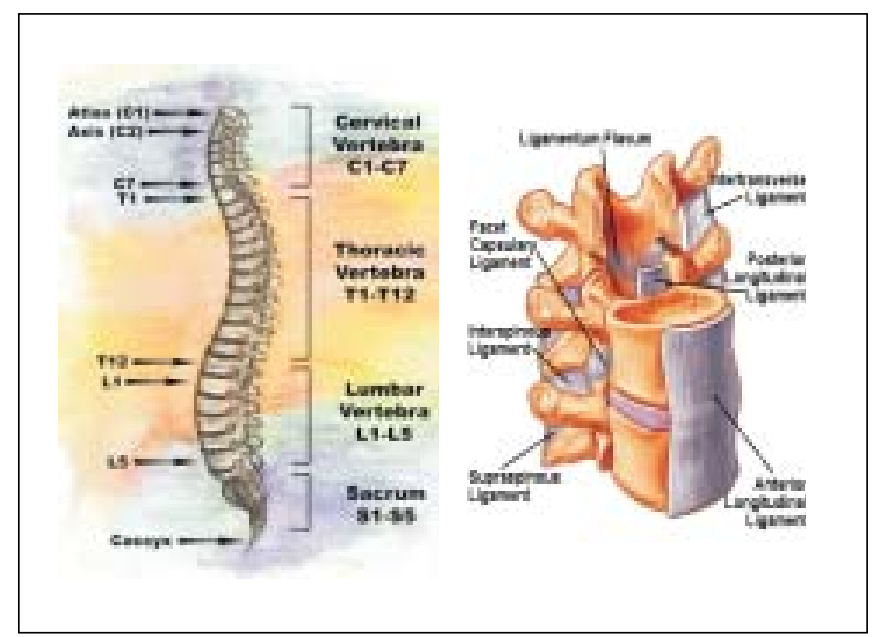

Figure 1: The human spine showing the different regions. Various components of the vertebrae along with the interposing disc are depicted

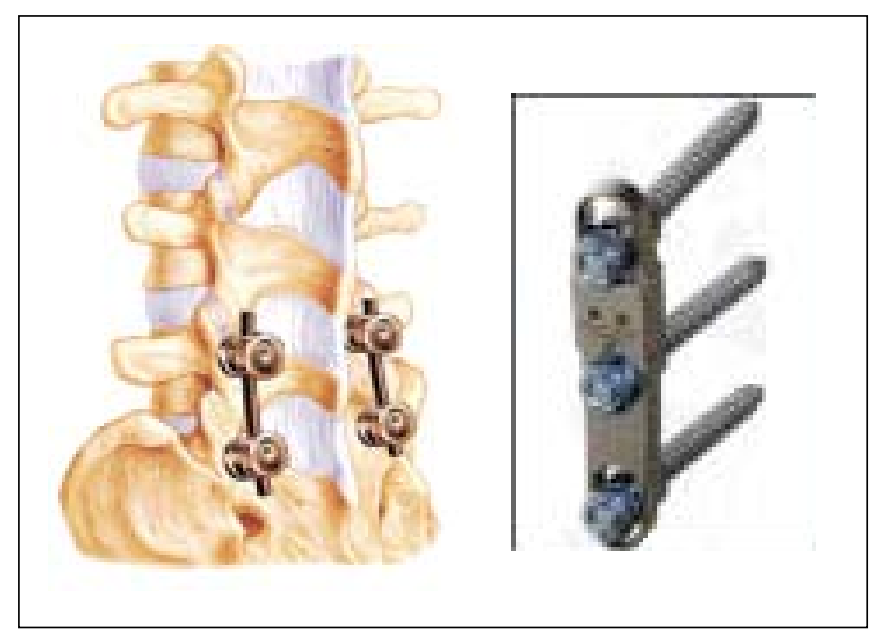

Figure 2: A decompressed segment is stabilized using a system of Rods/plates attached to the pedicle screws 
these procedures may lead to spinal instability. (Spinal instability may be present in patients without surgery for other reasons, like spinal degeneration.) Fusion of the spinal segment may be indicated in such cases.

In recent decades, surgeons have begun to supplement spinal fusion techniques with a wide variety of internal fixation devices. ${ }^{[1,2]}$ Internal fixation devices, within the context of this article, are longitudinal rods or plates that are attached to the screws placed within the pedicles (Figure 2). As can be visualized, the strength of the stabilized segment will depend upon the soundness of the screw fixation within the pedicles and the design of the fixation system itself. Strength may be increased in several manners: by attaching a (or more than one) cross member(s) to the longitudinal rods, using a combination of screws and hooks, triangulation of screws, etc. as shown in (Figures 2). Spinal implants are mechanical devices; they share loads with the spinal segment(s). Consequently, many of the issues associated with the spinal implants are mechanical in nature. Spinal implants differ from one another in many aspects, particularly in the site and method of attachment to the spine, the specific design, construction, and assembly of the implant components and the type of biomaterials used, to name just a few variables. This article provides a brief review of a few clinically relevant variables specifically related to pedicle screw systems. The studies reviewed deal with simple testing involving plastic vertebrae models to testing as sophisticated as the finite element models of the spinal segments. The limitations of each type of investigation are provided for a proper interpretation of the results, and their clinical relevance.

\section{Assembled device testing using plastic vertebrae models}

The main purpose of transpedicular screw fixation is to aid in the reduction and stabilization by immobilizing one or more spinal motion segments in order to facilitate bony fusion. However, in order for the implant to be effective, it must be able to withstand, without failure, the forces created in the spine during daily activities and to maintain the necessary position of the motion segments during the process of bony fusion. ${ }^{[3-10]}$ As a first step in the sequence of the evaluating process, a standard test protocol using artificial spine models was developed to characterize the devices, including their likely failure modes. ${ }^{[11]}$ Cunningham et al expanded upon this technique to provide comparisons of various pedicle screw spinal fixation devices in terms of static loads and loads $v$ s number of cycles to failure in bending-compression mode. ${ }^{[4]}$ Goel and associates have undertaken similar studies for the Kaneda anterior and DDS ${ }^{\circledR}$ posterior spinal devices. ${ }^{[12,13]}$

For the Kaneda system, the plastic vertebral bodies and rubber disk sub-assemblies, paraspinal rods, paraspinal nuts, and rod coupler were assembled into their correct positions (Figure 3A). Test fixtures were attached to the superior- and inferior-most surfaces of the assembly for testing within the electro-hydraulic MTS testing system. The stabilized artificial spine specimens were assigned to two groups: bending compression quasi-static group (three specimens) and bending compression cyclic test group (nine specimens). The failure load in the quasi-static bending mode was $806.3 \pm 6 \mathrm{~N}$. In the bending fatigue mode, the endurance/fatigue limit of the device was found to be $380 \mathrm{~N}$ with an accompanying bending moment of $\approx 13.57 \mathrm{Nm}$ (Figure 4). Below about $380 \mathrm{~N}$, the device could withstand the applied load for an unlimited number of cycles [specimens denoted with arrows in (Figure 4).

The fatigue failures observed in specimens ranged from a complete to partial breakage of the threaded paraspinal rods (Figure 5A) as opposed to failure due to permanent deformation of the rods in the quasi-static bending test specimens.

Similar tests on the DDS ${ }^{\circledR}$ posterior pedicle screw-rod system revealed that fatigue failure of the longitudinal rods also occurred at the location of the stress raisers (Figure 5B). ${ }^{[12]}$ One such location was in the rods at the screw-rod interface. The pedicle screw head design allowed the rod to be positioned within them without a need to contouring it. The locking nut mechanism that holds the rod in place, however, induced high contact stresses in the rods. The rods were prone to fail in fatigue mode at these locations. With the development of more versatile pedicle-rod screw systems, the clinical ease in implanting the device may improve,

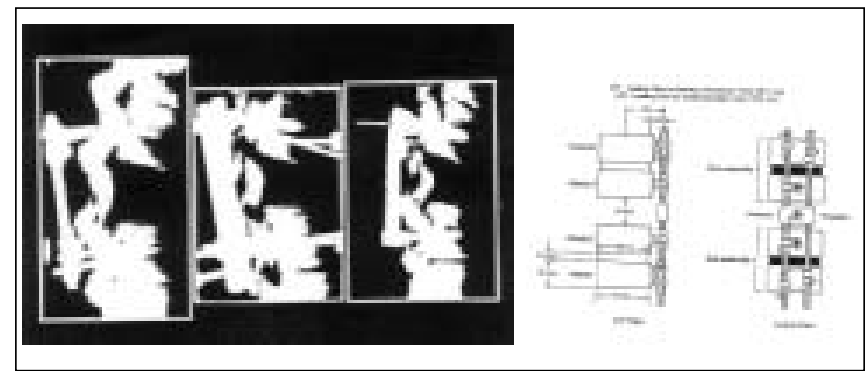

Figure 3: A corpectomy (missing vertebra) model was developed to assess the likely failure types, sites and corresponding loads, of a spinal implant using (A) plastic vertebrae, and (B) actual spinal segments. The applied axial load can be cyclic or static in nature. Due to off-center application of the load, the implant assembly is subjected to axial compression and bending moment. (Adapted from Goel et al. ${ }^{[26]}$ and Wittenberg et al. ${ }^{[78]}$ )

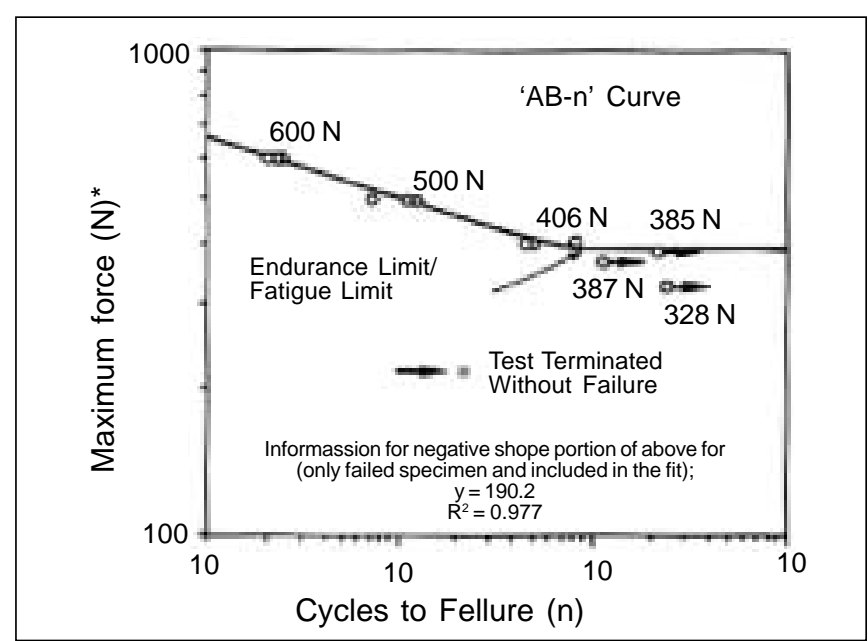

Figure 4: The load decreased with increase in number of cycles to failure of the assembled device until the endurance limit of the device. (Adapted from Goel et al. ${ }^{[26]}$ ) 


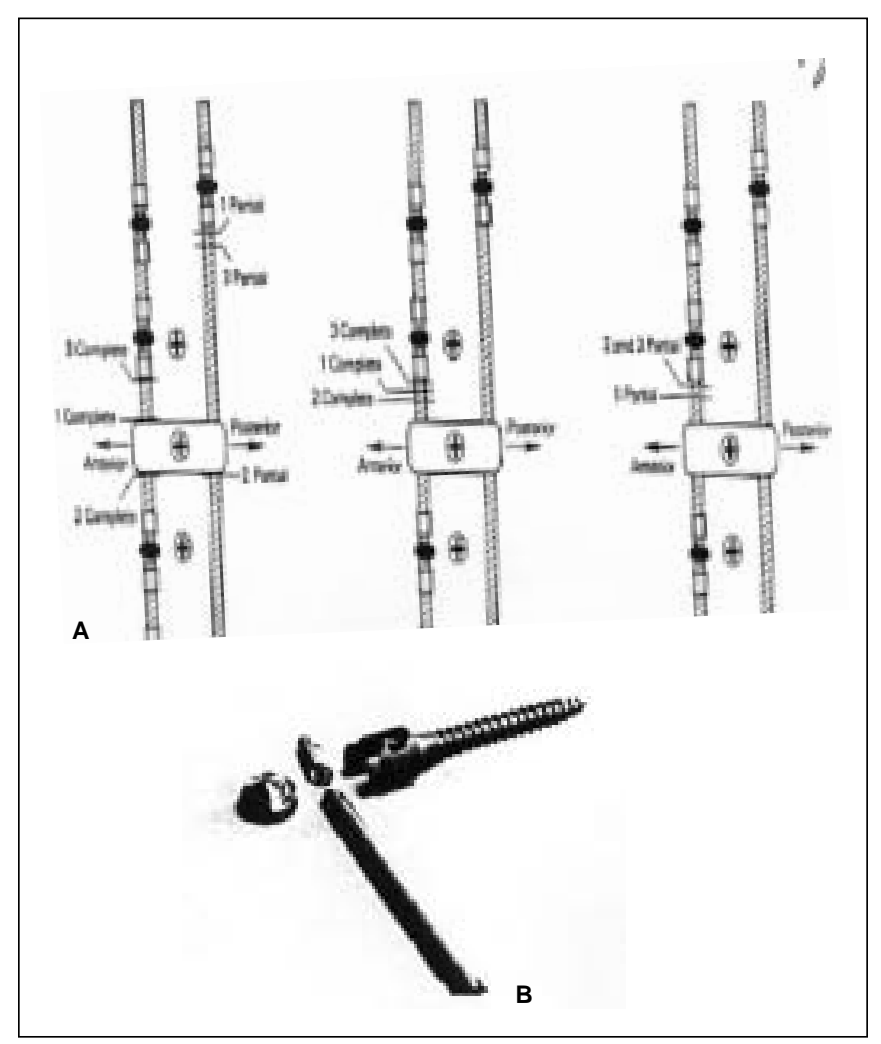

Figure 5: The device failure during cyclic loading occurred at the location of the stress raisers in the spinal system. (A) For the Kaneda device, the failures occurred in the threaded rods adjacent to The couplers or nuts. (B) For the DDS ${ }^{\circledR}$ device one of the failure sites Was the interface between the rod/cable, screw head and locking nut assembly. (Adapted from Goel et al. ${ }^{[26]}$ and Clausen et al.. ${ }^{[11]}$ )

but at the likely expense of creating more stress concentration sites. Clearly, much coordination between the implant design engineer and the clinician is needed to ensure that these failures are minimized. Moreover, in the event of failure, the failure locations will not be clinically problematic.

The results of the above described test protocol will vary with the size, shape and configuration of the assembled devices. According to Pool and Gaines, based on theoretical analysis of various plate and rod constructs, decreasing the rod diameter from 0.25 in. to $3 / 16$ in. (a $25 \%$ decrease) resulted in a $68 \%$ loss of stiffness and a $58 \%$ loss of bending strength, secondary to the cross-sectional area change. ${ }^{[14]}$ Decreasing the crosssectional area of plates leads to smaller area moments of inertia and a corresponding decrease in stiffness and strength. The use of transverse rods provides a direct connection between the two longitudinal rods of the pedicle screw construct and is presumed to increase the stability of the spinal construct, especially in rotation.

Studies of the assembled implants using 'worse-case', 'missing vertebra' artificial models are important in revealing the weak points of a particular device, but they do not show how its performance may be effected by the bone-screw interface characteristics. This issue is discussed next.
Bone-screw interface - assembled device testing using spine vertebrae models

Wittenberg et al., subjected five different spinal fixation systems to a cyclic flexion-compression loads for 100,000 cycles using a missing vertebrae model (L3 corpectomy) in fresh lumbosacral calf spines (Figure 3B). ${ }^{[15]}$ Failure of AO Schanz screws occurred in three of the six constructs at a mean of 73,300 cycles. The Steffee screws failed in four of the five constructs at a mean of 20,800 cycles. The rods of the Kluger fixateur interne broke in four of the five constructs at a mean of 47,800 cycles, with one screw slipping at 11,000 cycles. The authors felt that longer implants can enhance the possibility of fusion since less strain is present across the stabilizing segment. However, the authors argued that increased strain at adjacent levels to the missing vertebra produced by these long implants could be associated with early degeneration and destabilization. Thus, short segmental fixation might be preferred. This study delineated the importance of the strength across the bone-screw interface despite several shortcomings including deterioration of specimen quality over time.

\section{Bone-screw interface - axial pullout type testing}

Strength across the screw and bone (e.g. pedicle) interface influences the success of transpedicular fixation systems. ${ }^{[16-22]}$ This becomes especially vital when the spine is osteoporotic and the screw is subjected to relevant types of cyclic loads. ${ }^{[20,22]}$ Axial pullout of transpedicular screws, although not a likely clinical mode of failure, is a popular experimental testing mode for evaluating screw-bone interface biomechanics. ${ }^{[22]} \mathrm{A}$ wide variety of testing protocols to accomplish the pullout tests have been used by different groups. The resulting numerous testing variables make it difficult to compare results (e.g., pullout strength) between groups. ${ }^{[22]}$ Thus, the data provided in the following paragraphs must be considered with caution.

Bone material density (BMD) had a strong influence on axial pullout force. ${ }^{[16-22]}$ Soshi et al., performed screw pull-out tests using cadaveric lumbar Vertebrae. ${ }^{[23]}$ For a $7.0 \mathrm{~mm}$ screw, the pull-out force was $1,056.4 \mathrm{~N}$ in the normal group, while it was 495.6 $\mathrm{N}$ in the Grade I osteoporosis and 300.0 N (or less) in the Grade II and Grade II osteoporosis groups. Thus the maximum resistance of a screw pull-out force was found to be affected by the severity of the osteoporosis (Figure 6). Human lumbosacral spines were instrumented with three different fixators: Steffee plates, AO fixateur Interne, and Kluger fixateur Interne and tested. ${ }^{[24]}$ Of five specimens with a mean density of $88 \mathrm{mg} /$ $\mathrm{cm}^{3}$, one screw loosened. More than one screw loosened in six specimens with a mean density of $63 \mathrm{mg} / \mathrm{cm}^{3}$, and no screw loosened in four specimens with a mean density of $114 \mathrm{mg} / \mathrm{cm}^{3}$. In calf vertebral bodies of higher density $\left(146 \mathrm{mg} / \mathrm{cm}^{3}\right)$, the forces were significantly higher than in the human vertebral bodies. The authors concluded that mineral density correlates well with the fixation strength of intrapedicular screws. As such, a low bone mineral density in a patient may be a contraindication for the use of pedicle screw devices. 


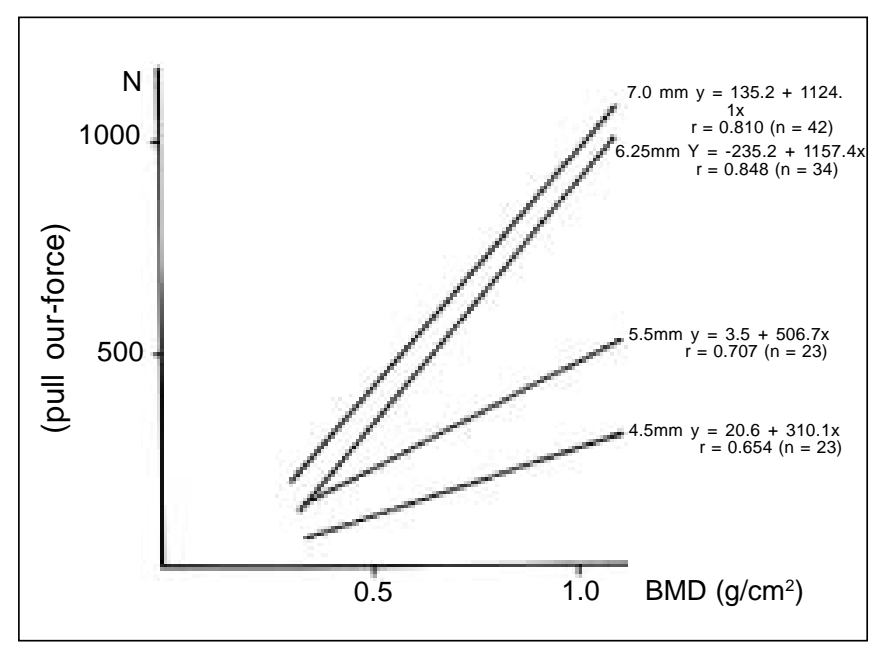

Figure 6: Correlation between bone mineral density and pullout force. (Adapted from Soshi et al. ${ }^{[74]}$ )

The pullout strength is also related to the screw insertional torque as well. Zdeblick et al., subjected thirty human cadaveric lumbar vertebrae, which were instrumented with $6.5 \mathrm{~mm}$ pedicle screws, to cyclic pullout axial forces. ${ }^{[25]}$ The maximum torque achieved during screw insertion was digitally recorded. A linear correlation existed between the insertional torque when tapping or when inserting a screw and the number of cycles to failure. According to the authors, insertional torque is a good predictor of failure.

In another recent study, the screw pullout strength was correlated to BMD as well as screw insertion torque using cervical spine specimens and the anterior screws. ${ }^{[26]}$ The BMD and screw insertional torque, as expected, were significantly related to the pullout strength. From a statistical perspective, BMD accounted for $28.3 \%$ and peak insertion torque accounted for $76.9 \%$ of the observed variability in pullout force. The authors, in an effort to improve the predictive power of regression model, defined a parameter, termed 'Holding Index' that took into account both the BMD and insertional torque. 'Holding Index' (BMD x screw insertional torque) correlated with the pullout force as follows:

Pullout Force $=647.3 \times$ Holding Index - $13.52(P<0.0001$, $\mathrm{r}=0.92)$.

The predictive power of the model accounted for $84 \%$ of the variability observed in pullout force. Although, the study was done for anterior screws and on cervical vertebral bodies, the authors believe that a similar model will be applicable for the pedicle screwbone interface as well.

Strength at the bone-screw interface may also be altered by the screw orientation, its depth of penetration and other parameters associated with the design of a pedicle screw. The load deflection data of the screws to failure at the bone-screw interface revealed that anteromedial screw orientation, especially with rigid fixation, was stronger than screws placed along the anterolateral direction. ${ }^{[16]}$ This may be clinically important, especially in the early postoperative period. The results of a biomechanical study undertaken by Pashman et al. suggested that bending may be important in screw failure and, according to the above study, bending resistance may be increased by placing the screw in the anteromedial direction. ${ }^{[21]}$ Triangulation of Steffee screws and CD pedicle screws was accomplished by transverse plates specifically designed to increase fixation within the same vertebra. ${ }^{[27]}$ Three triangular constructs (CD, Steffee, and Krischner) provided significantly greater fixation than conventional pedicular or laminar hook systems (Table 1).

The strength of the bone-screw interface, for a given screw size (or fill within the pedicle cross section) increases with depth of screw penetration. The fixation stiffness $(\mathrm{Nm} / \mathrm{Deg})$ for screws which had about $80 \%$ penetration length was at least $80 \%$ of the $100 \%$ length strength value in any percent fill groups (Figure 7). ${ }^{[28]}$ Karg et al. compared the peak strength of screws at 50 and $100 \%$ penetration depth with the values at $80 \%$ penetration depth. ${ }^{[29]}$ The strength of the $50 \%$ depth of penetration group was $77 \%$ for flexion loads and $75 \%$ for torsion loads. By increasing the depth from 80 to $100 \%$, the strength increased by $154 \%$ for flexion loads and $124 \%$ for torsion loads. According to Weinstein et al., approximately $60 \%$ of the fixation strength of the thoracic and lumbar pedicles is in the pedicle itself, whereas $15-20 \%$ of the strength comes from the cancellous bone, and another 20 $25 \%$ from the anterior cortex. ${ }^{[30]}$ These authors, however, felt that it is not necessary to routinely engage the anterior cortex; the risk for damage of the major vessels may exceed the benefit which is gained by engaging the anterior cortex.

The size of the pedicle screw also effects the bone-screw interface performance, especially in the vertebral bodies of normal bone quality. ${ }^{[28,29,31-34]}$ Karg et al. reported that the mean pullout force of 7-mm diameter pedicle screws was always greater than 6 -mm screws of the same design. ${ }^{[29]}$ The axial pullout force of Schanz screws was significantly increased with an increase in screw diameter, although different authors have reported different strength values. ${ }^{[32-34]}$

Besides the screw diameter, the strength of the interface is also determined by the degree of fill of the screw with respect to the pedicle cross-section. Increased percent fill increased vertebral fixation strength in a linear manner, especially if the depth of screw penetration was at least $80 \%$ (Figure 8). ${ }^{[28]}$ Zdeblick et al. found an inverse relationship between the pedicle width and cycles to failure, for a given screw size. ${ }^{[25]}$ These biomechanical studies recommend that a surgeon should select a screw that has a diameter close to the inner pedicle diameter in order to achieve a good bone screw interface. Screws with too large of a diameter may fracture pedicle cortical wall risking nerve root injury. Therefore, one must

Table 1: Comparative pullout load to failure (Adapted from Goel and Pope ${ }^{[68]}$ )

\begin{tabular}{ll}
\hline Construct load to failure & (N) \\
Laminar rods & 99.4 \\
Single CD pedicle screw & 108.0 \\
Single Steffee pedicle screw & 75.3 \\
Adjustable transverse plate & 114.0 \\
Triangulated pedicular screws with transverse plate & 151.0 \\
Triangulated CD pedicular screws with transverse plate & 115.0
\end{tabular}




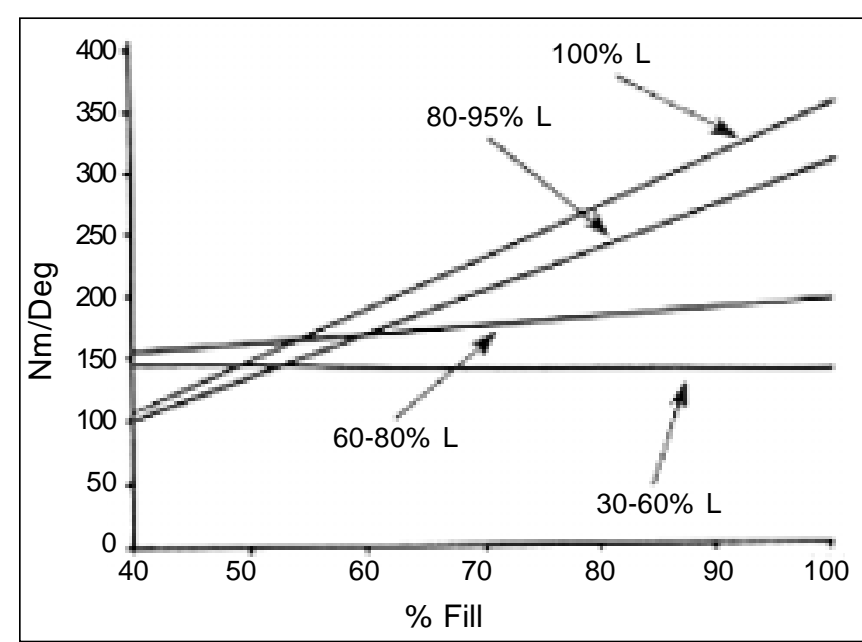

Figure 7: Initial stiffness of spine No. 1 plotted as a function of percent length for different ranges of percent fill (F). $30 \%$ to $50 \%$ F:R2 $=0.01, \mathrm{SE}=50.7 ; 50 \%$ to $60 \% \mathrm{~F}: \mathrm{R2}=0.003, \mathrm{SE}=42.6 ; 60 \%$ to $70 \% \mathrm{~F}: \mathrm{R} 2$ $=0.31, \mathrm{SE}=27.7 ; 70 \%$ to $80 \% \mathrm{~F}: \mathrm{R} 2=0.64, \mathrm{SE}=44.6 .80 \%$ to $100 \% \mathrm{~F}: \mathrm{R} 2$ $=0.86, \mathrm{SE}=31.8$ (Adapted from Brantly et al. ${ }^{[7]}$ )

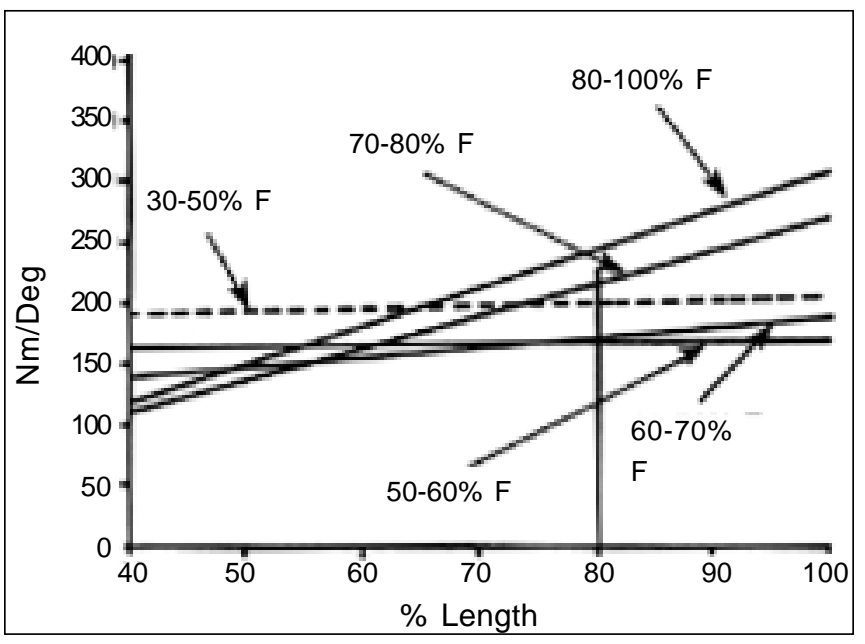

Figure 8: Initial stiffness of spine No. 1 (no L5) plotted as a function of percent fill for different ranges of percent length (L). $30 \%$ to $60 \%$ $L: R 2=0.01$, SE $=14.7 ; 60 \%$ to $80 \%$ L:R2 $=0.06$, SE $=39.8 ; 80 \%$ to $95 \%$ $L: R 2=0.73, S E=32.3 ; 100 \%$ L:R2 = 0.73, SE = 39.5 (Adapted from Brantly et al. ${ }^{[7]}$ )

confirm the size of the pedicle by CT-scan prior to surgery. Since the pedicles as well as other vertebral body dimensions are smaller in the thoracic and upper lumbar regions than those in the lower lumbar region, a surgeon must make appropriate selection of the screw in terms of its size and length. ${ }^{[35,36]}$

In terms of the screw itself, the biomechanical data supports the use of a screw that will fill the cancellous bone region of the pedicle and will penetrate up to eighty percent of the vertebral body along the pedicle axis. These recommendations are valid for vertebral bodies with normal bone quality (nonosteoporotic).

Bone-screw interface performance can be enhanced in a number of other ways. It is well known that bone cement (PMMA) can be used to enhance the pullout strengths of screws after injection into the pedicle hole. ${ }^{[23,34,37,38]}$ The mean pullout force increased from 709 to $1860 \mathrm{~N}$ for screws augmented with PMMA. ${ }^{[34]}$ Zindrick et al. showed significantly increased axial pullout forces for pedicle screws inserted with pressurized PMMA. ${ }^{[38]}$ Similar results were obtained by Soshi et al. (Figure 9). ${ }^{[23]}$ However, in Grade III group even with bone cement, the mean pullout force was very low (H”300 N). Thus, caution may be exercised when using pedicular screw systems for Grade III osteoporotic patients. Moreover, application of PMMA with pedicle screws increase the risk of damage to neural structures and its use is cautioned. ${ }^{[30,39]}$

Augmentation of the construct with offset laminar hooks has been recommended as a means of preventing fixation failure of the pedicle screw systems. The laminar hooks decrease the load transmitted between bone and pedicle screws, thereby protecting both screws and the bone. ${ }^{[40]}$ The use of pedicle screws with offset hooks at two adjacent levels improved the fixation significantly, increasing the pullout force to twice the expected value (Table $2) .{ }^{[41]}$ Such studies further reinforce the idea that the usefulness of hook devices in the osteoporotic bone is greater than pedicle screw systems. The authors further stated that penetration of the anterior cortex may add $30 \%$ to the pullout strength. Perhaps this may be considered in the osteoporotic spine, especially for patients with Grade III osteoporosis.

Finally, the parameters related to the screw hole (e.g., tapping drilling, damage, etc.) may also play a role in the performance of the bone-screw interface. In normal bone the method of screw hole preparation did not significantly affect the quality of fixation. ${ }^{[41]}$ However, in the osteoporotic spine, either an untapped screw hole or the tapping of a screw hole with a $5.5 \mathrm{~mm}$ tap for the $6.5 \mathrm{~mm}$ screw improved the pullout force by a statistically significant amount (Table 2). In normal spines, it was possible to salvage a hole in which screw threads had been stripped by placing corticocancellous graft int the hole before replacing the screw. However, in osteoporotic spines, the use of corticocancellous graft in a screw hole destroyed by stripping did not increase the strength of the fixation.

Ligamentous spinal segment based evaluations (construct testing)

The previously discussed studies describing interactions at the bone-screw interface, by virtue of their design, do not show how

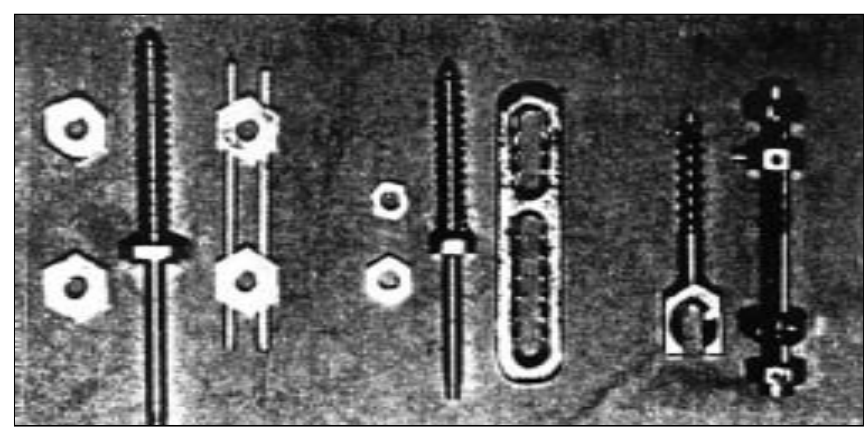

Figure 9: The three different pedicle screw devices used for stabilizing a decompressed spinal segment \{ (A) RTS: (B) Steffee, and (C) Crock\}. The principal difference in these devices was in terms of their rigidity, most probably the least stiff device was the 'Crock' System (Adapted from Gwon et al. ${ }^{[32]}$ ) 


\section{Table 2: Pullout force and density by construct type (Adapted from Halovorson et al. ${ }^{[41]}$ )}

\begin{tabular}{lccc}
\hline $\begin{array}{l}\text { Screw construct } \\
(n=8 \text { except as }\end{array}$ & Density $\left(\mathrm{g} / \mathrm{cm}^{2}\right)$ & $\begin{array}{c}\text { Pullout force } \\
\text { observed }(\mathrm{N})\end{array}$ & $\begin{array}{c}\text { Pullout force } \\
\text { calculated }(\mathrm{N})\end{array}$ \\
$\begin{array}{l}\text { noted }) \\
\text { Untapped, normal }\end{array}$ & $1.1 .27 \pm 0.032$ & $1654 \pm 208$ & - \\
$\begin{array}{l}\text { Untapped, } \\
\text { osteoporotic }\end{array}$ & $0.860 \pm 0.374$ & $350.4 \pm 115^{\star}$ & - \\
$5.5 \mathrm{~mm}$ tap, normal & $1.093 \pm 0.609$ & $1028 \pm 552$ & - \\
$5.5 \mathrm{~mm}$ tap, & $0.869 \pm 0.400$ & $400.3 \pm 205^{\star}$ & - \\
$\begin{array}{l}\text { osteoporotic } \\
6.5 \mathrm{~mm} \text { tap, normal }\end{array}$ & $1.196 \pm 0.949$ & $1631 \pm 413$ & - \\
$\begin{array}{l}6.5 \mathrm{~mm} \text { tap, } \\
\text { osteoporotic }\end{array}$ & $0.777 \pm 0.330$ & $63.55 \pm 48.2$ & - \\
$\begin{array}{l}\text { Stripped and packed } \\
\text { with bone chip normal }\end{array}$ & $1.196 \pm 0.949$ & $1425 \pm 544$ & - \\
$\begin{array}{l}\text { Osteoporotic } \\
\text { One screw, one }\end{array}$ & $0.777 \pm 0.330$ & $61.41 \pm 47.0$ & - \\
hook $(n=4)$ & $1.016 \pm 0.801$ & $812.0 \pm 186$ & 900.4 \\
$\begin{array}{l}\text { One screw, two } \\
\text { hooks }(n=4)\end{array}$ & $0.970 \pm 0.116$ & $1423.0 \pm 432$ & 739.9 \\
\hline${ }^{*} P<0.0003$ & & & \\
\hline
\end{tabular}

effective a device may be in imparting stability to the decompressed segment. In vitro testing undertaken by a number of investigators shed light on this aspect of pedicle screw based device performance.

Studies investigating the overall strength afforded by a pedicle screw construct in stabilizing a disrupted ligamentous segment within the spine have demonstrated that most of the constructs tested imparted significant stability to the injured specimens in flexion/extension, although the degree of stability imparted varied among the various constructs. ${ }^{[3,4,7,19,42-46]}$

Gwon et $\mathrm{al}^{[47]}$ prepared ten fresh intact ligamentous L1-S1 specimens using well established techniques, and determined their three-dimensional load-displacement behaviors in flexion (FLX), extension (EXT), right and left lateral bending (RLB and LLB) and left and right axial rotation (LAR and RAR). ${ }^{[3,48-55]}$ The specimens was destabilized and the 'injured' segment was stabilized in a sequential manner using three different devices (Figure 10): $\mathrm{RTS}^{[49]}$ - spinal rod-transpedicular screw system, Figure 10A; VSP - Steffee System, Figure 10B; and CRK ${ }^{[56]}$ —Crock device, (Figure 10C). The load-displacement fixation data of the intact and stabilized specimens were compared to determine the efficacy of a particular fixation device in restoring stability across the injured/disrupted segment. The devices resulted in a $70 \%$

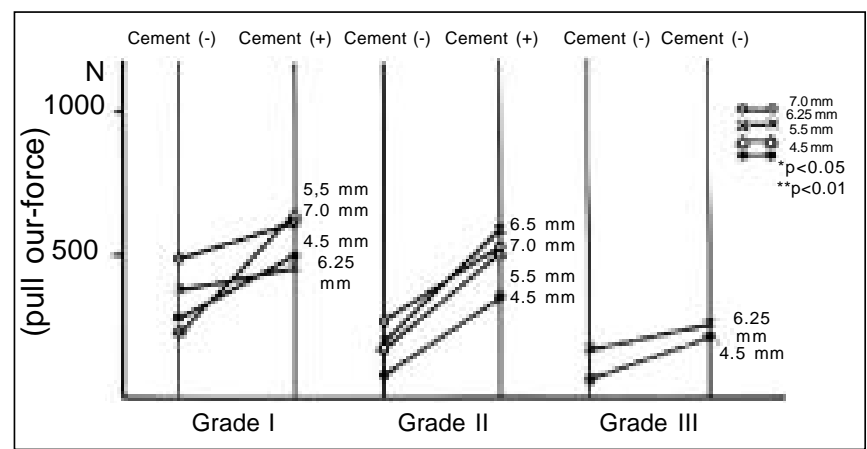

Figure 10: Comparison of pullout force between the specimens without and with bone cement (Adapted from Soshi et al. ${ }^{[74]}$ ) reduction in motion across the L4-5 level in comparison to the intact data $(P<0.01)$. The difference among the three different devices was not statistically significant.

Cunningham et al. evaluated 12 different pedicle screw constructs and found the ISOLA rod system (with two transverse rods placed $20 \mathrm{~mm}$ from the pedicle screws) to have the highest stiffness and strength values compared to the other rod and plate systems. ${ }^{[4]}$ Pintar et al. found that one transverse fixator worked as well as two until a longitudinal rod length of $>15 \mathrm{~cm}$ (constructs spanning more than three vertebra) was reached. ${ }^{[57]}$ Abumi et al. found that transpedicular fixation devices with transverse rods were generally more stable than systems without. ${ }^{[3]}$ The transpedicular external fixator (EF, Figure 11) was the only construct able to significantly limit axial rotation to that approaching an intact spine. Skalli et al. determined, using a finite element model of a Cotrel-Dubousset-like device in which the device was tested first with transverse rods left intact and then with the transverse rods removed, that removing the transverse rods in the model significantly increased the mobility of the instrumented segement. ${ }^{[9]}$ Thus, the benefits of transverse rods in imparting greater stability to the spine and construct appear clear.

In summary, although in vitro tests do not simulate the effects of muscles, the findings are still relevant. The results of the above in vitro experimental studies (and similar studies as well) ${ }^{[24,46]}$ suggest that, on a short-term basis, posterior fixation devices are 'capable' of imparting stability to an 'injured' segment. The degree of stability imparted, at least in the physiological range of motion, does not vary significantly with the screw size, implant shape, or other variables. The stiffness of material (steel) used for fabrication is many orders of magnitude higher than the body/ligamentous spinal components responsible for the stability in an intact 'normal'

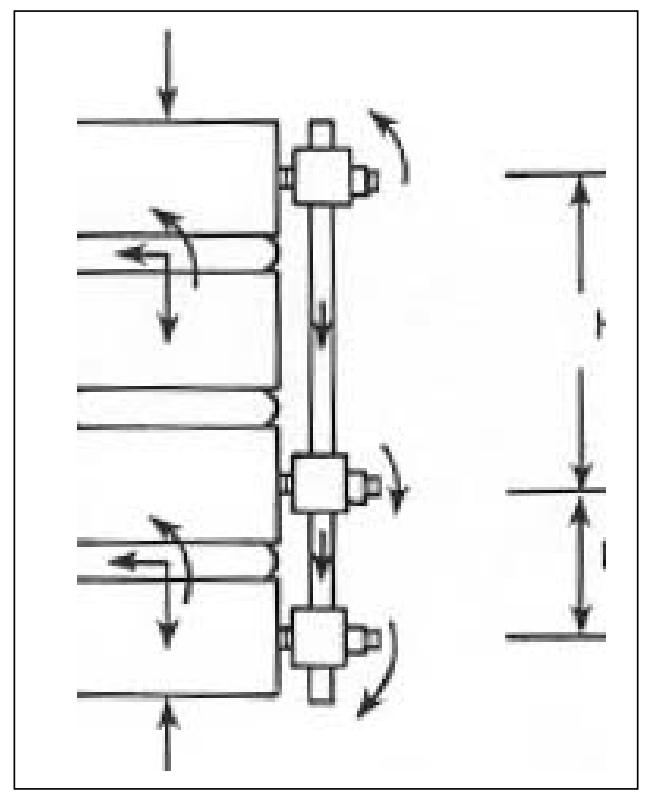

Figure 11: Internal moments and forces in $6.35 \mathrm{~mm}$ rod and $4.76 \mathrm{~mm}$ rod constructs for an applied axial compressive load of $445 \mathrm{~N}$ (Adapted from Duffield et el..[9]) 
specimen. As a result, slight variations in the shape and sizes of pedicle screw devices are not likely to affect the load-displacement behavior to any significant level.

\section{Analytical models for evaluation of spinal devices}

Living tissue is known to respond to changes in stresses and strains over time (bone adaptive remodeling process). Accordingly, changes occur following spinal surgery as well. The goal of biomechanical investigations is to define relationships, among clinical observations following surgery (like spinal stenosis, disc degeneration, stress-induced osteopenia, etc.) and the mechanical environment including the structural characteristics of a device. In Vitro data cannot address these questions. It is our hypothesis that devices are likely to alter the stress, strain, and force distribution within the stabilizing segment as well as the adjacent segments in comparison to an intact 'normal' specimen. Thus, the quantification of such parameters may be helpful.

\section{Finite element models}

Duffield et al. have shown that the longitudinal rod or plate size and cross-sectional shape, the anterior-posterior (AP) distance from the point of application of axial load to the plane of the longitudinal elements (designated H1), and the longitudinal distance between screws (designated H2) are all factors which affect the axial stiffness of posterior implant constructs (Figure 12). ${ }^{[5]}$ The authors state that a shorter $\mathrm{H} 1$ and/or H2 length will result in a stiffer construct and that this result, in conjunction with a decrease in vertebral column axial stiffness, can cause a significant reduction in load sharing by the vertebral column. Thus, there may be a trade-off between construct rigidity and subsequently faster, stiffer fusion mass formation and stress shielding effects caused by high impact rigidity.

Intact finite models of ligamentous motion segments (L3-L4 and L3-L5) were appropriately modified to simulate the use of a

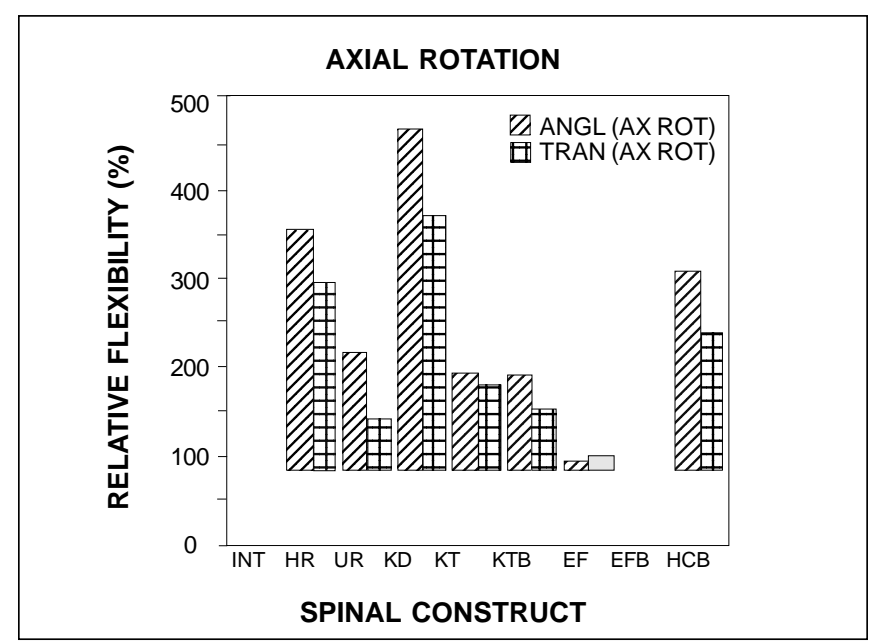

Figure 12: Compartive results for the tested spinal constructs in axial rotational mode. Each bar represents a relative angular or translatory ROM of a construct at the injury site as compared to the intact spine (INT = 0). Bars above the zero line represent a less stable construct and bars below the zero line represent a more stable construct (Adapted from Abumi et al. ${ }^{[3]}$ ) screw-plate device based on the Steffee (VSP) system and various fusion techniques. ${ }^{[6,58]}$ Three separate models were developed: bilateral plates and bilateral fusion before healing, unilateral plate and bilateral fusion before healing, and bilateral plates with an interbody bone graft before healing. These models simulated the behavior immediately following surgery. Following healing, the bone mass or interbody bone graft transmits tensile as well as compressive loads. The case wherein the graft is fully healed was also simulated by permitting force transmission through elements representing bone graft/bone mass in the models. Models were also constructed to consider the metal plates and/or screws removed in order to study the effects of removing the device.

The interbody bone graft transmitted about $80 \%$ of the axial load as compared to $96 \%$ transmitted by an intact disc in an intact model. Thus, the predicted stress results revealed the presence of some stress-shielding effects from the device. The removal of devices after solid fusion led to a marginal increase of stresses in cancellous bone regions compared to the devices not removed cases, but the stresses were still lower than those in the intact motion segment. This implies that the stress-shielding effects are likely to occur with the fusion alone as well as with instrumentation. Clinical evidence in support of this is available in the literature. Penta et al. assessed the disc degeneration 10 years after anterior lumbar interbody fusion using MRI ${ }^{[59]}$ The authors found that in those patients where anterior spinal fusion was the primary procedure, the incidence of significant spinal stenosis developing at the adjacent level was only $2.5 \%$. This lack of association between anterior interbody fusion and the development of spinal stenosis was in marked contrast to a study of the long-term effects of posterior fusion in which significant spinal stenosis developed in $30 \%$ of the patients, both at the involved and level above. These clinical observations support the analytical predictions that degenerative changes may occur with and without spinal instrumentation at the fused and adjacent levels.

\section{Conclusions}

The success of lumbar fusion depends on local factors (mechanical environment, fusion site preparation, blood supply, bone graft sources and quantity), systemic factors (osteoporosis, hormones, drugs and smoking), and possibly biologic enhancements (electrical stimulation, growth factors), etc. ${ }^{[60,61]}$ Clinically, the most common approach to the problem of nonunions after spinal fusion has focused on control of the mechanical environment, as described above. Accordingly, it is no surprise to find a vast amount of information delineating the biomechanical effects of a large number of spinal instrumentations in literature. The peer-reviewed biomechanical literature, in conjunction with the clinical follow-up studies, suggest the following:

- The use of spinal devices promotes/enhances the fusion healing process.

- Spinal devices have adequate strength (quasi-static and fatigue) to restore spinal stability.

- Bone-screw interface characteristics can influence the 
successful outcome of the spinal instrumentation.

- The stiffness of the material (steel) used for fabrication of the spinal device is many orders of magnitude higher than the bony/ligamentous spinal components responsible for the stability in an intact 'normal' specimen. Consequently, slight variations in the shapes and sizes of pedicle screw devices, in general, are not likely to affect the load-displacement behavior in the physiological range to any significant level.

- The stress related effects of the spinal devices on the quality of bone are minimal. Bone density changes following spinal fusion occur even without the use of spinal instrumentation. Furthermore, density changes seem to be mainly related to the degenerative process itself rather than the use of a spinal device per se.

- It is not possible to delineate the most appropriate spinal fixation device, based on the biomechanical performance alone. Future studies of these devices, in line with other areas of orthopaedic biomechanics research, will undoubtedly require development of new protocols, both experimental and analytical. For example, techniques are needed to study the biomechanies of spinal fixation devices in the presence of muscles. ${ }^{[62]}$ In order to provide a more comprehensive understanding of spinal stabilization, the above described studies need to be complemented with similar in-depth in vivo investigations. ${ }^{[63-67]}$

Finally, it must be noted that biomechanical tests in themselves are not sufficient to assess the $i n$ situ performance of a spinal implant. The actual success rate of a spinal device can only be determined by the clinical follow-up studies. Proper biomechanical investigations of a device, however, will help achieve this goal in a relatively shorter period of time, and with reduced resource commitment. Above all, biomechanical investigations, in conjunction with other studies, will ensure increased patient safety.

\section{References}

1. Hanley EN. The indications for lumbar spinal fusion with and without instrumentation. Spine 1995;20:143S-53S.

2. Sonntag VK, Marciano FF. Is fusion indicated for lumbar spinal disorders? Spine 1995;20:S138-42.

3. Abumi K, Panjabi MM, Duranceu J. Biomechanical evaluation of spinal fixation devices. Part III: Stability provided by six spinal fixation devices and interbody bone graft. Spine 1989;14:1239-55.

4. Cunningham BW, Sefter JC, Shono Y, McAfee PC. Static and cyclical biomechanical analysis of pedicle serew spinal constructs. Spine 1993;18:1677-88.

5. Duffield RC, Carson WL, Chen L, Voth B. Longitudinal element size effect on load sharing, internal loads, and fatigue life of tri-level spinal implant constructs. Spine 1993;18:1695-703

6. Goel VK, Kim YE, Lim TH, Weinstein JN. An Analytical Investigation of the Mechanies of Spinal Instrumentation. Spine 1988;13:1003-10.

7. Gurwitz GS, Dawson JM, McNamara MJ, Federspiel CF, Spengler DM. Biomechanical Analysis of Three Surgical Approaches for Lumbar Burst Fractures Using Short-Segment Instrumentation. Spine 1993;18:977-82.

8. Krag MH. Biomechanies of thoracolumar spinal fixation. A review. Spine 1991:16:S84-99.

9. Skalli W, Robin S, Lavaste F, Dubousset J. A biomechanical analysis of short segment spinal fixation using a three-dimensional geometric and mechanical model. Spine 1993;18:536-45

10. Yamagata M, Kitahara H, Minami S, Takahashi K, Isobe K, Moriya H, et al. Mechanical stability of the pedicle screw fixation systems for the lumbar spine. Spine $1992 ; 17:$ S $51-4$

11. Beynnon BD, Krag MH, Pope MH, Frymoyer JW, Haugh LD. Fatigue evaluation of a new spinal implant. ASME-Advances in Bioengineering, 1986. p. 56-7.
12. Clausen JD, Goel VK, Kong WZ, Sairyo K, Pfeiffer M, Kim YS. A protocol to evaluate cyclic behavior of pedicle screw-cable systems.

13. Goel VK, Winterbottom JM, Weinstein JN. A method for the fatigue testing of pedicle screw fixation devices. $J$ Biomech 1994;27:1259-69.

14. Pool HA, Gaines RW. Biomechanies of transpedicular serew spinal implant systems. Spine 1992;6:27-43.

15. Wittenberg RH, Shea M, Edwards WT, Swartz DE, White AA, Hayes WC A biomechanical study of the fatigue characteristics of thoracolumbar fixation implants in a calf spine model. Spine 1992;17:S121-7.

16. Carlson GD, Abitol .J.J, Anderson DR, Krag MH, Kostuik .JP, Woo SL, et al. Screw fixation in the human sacrum - An in vitro study of the biomechanies of fixation. Spine 1992;17:S196-S203.

17. Coe JD, Warden KE, Herzug MA, McAfee PC. Influence of bone mineral density on the fixation of the thoracolumbar implants. A comparative study of transpedicular screws, laminar hooks, and spinous process wires. Spine 1990;15:902-7.

18. Grobler L.J, Novotny .JE, Wilder DG, Frymover .JW, Pope MH. L4-5 Isthmic spondylolisthesis - A biomechanical analysis comparing stability in L4-5 and L5S1 isthmic spondylolisthesis. Spine 1994;19:222-7.

19. MeCord DH, Cunningham BW, Shono Y, Myers JJ, McAfee PC. Biomechanical analysis of lumbosacral fixation. Spine 1992;17:S235-S423

20. Okuyama K, Sato K, Abe E, Inaba H, Shimada Y, Murai H. Stability of transpedicle screwing for the osteoporotic spine - An in vitro study of the mechanical stability Spine 1993;18:2240-5.

21. Pashman RS, Hu SS, Schendel M.J, Bradford DS. Sacral screw loads in lumbosacral fixation for spinal deformity. Spine 1993;18:2465-70.

22. Pfeifer M, Gilbertson LG, Goel VK, et al. Effect of specimen fixation method on the pullout tests of pedicle screws. Spine 1996;21:1037-44.

23. Soshi S, Shiba R, Kondo H, Murota K. An experimental study on transpedicular serew fixation in relation to osteoporosis of the lumbar spine. Spine 1991;16:133541.

24. Wittenberg RH, Shea M, Swartz DE, Lee KS, White AA $3^{\text {rd }}$, Hayes WC. Importance of bone mineral density in instrumented spine fusions. Spine 1991;16:647-52.

25. Zdeblick TA, Kunz DN, Cooke ME, McCabe R. Pedicle screw pullout strength correlation with insertional torque. Spine 1993;18:1673-6.

26. Ryken TC, Clausen .JD, Traynelis VC, Goel VK. Biomechanical analysis of bone mineral density, insertion technique, screw torque, and holding strength of anterior cervical plate screws. J Neurosurg 1995;83:324-9.

27. Ruland CM, McAfee PC, Warden KE, Cunningham BW. Triangulation of pedicular instrumentation. A biomechanical analysis. Spine 1991;16:S270-6.

28. Brantly AGU, Mayfield JK, Koeneman JB, Clark RC. The effect of pedicle serew fit. An in vitro study. Spine 1994;19:1752-8.

29. Krag MH, Beynnon BD, Pope MH, DeCoster TA. Depth of insertion of transpedicular vertebral screws into human vertebrae: Effect upon screw-vertebra interface strength. $J$ Spinal Discord 1989;1:287-94.

30. Weinstein JN, Rydevik BL, Rauschning W. Anatomic and technical considerations of pedicle screw fixation. Clin Orthop 1992;284:34-46.

31. McLain RF, Fry MF, Moseley TA, Sharkey NA. Lumbar pedicle screw salvage. Pullout testing of three pedicle screw designs. J Spinal Discord 1995;8:62-8

32. Skinner R, Maybee J, Transfeldt E, Venter R, Chalmers W. Experimental pullout testing and comparison of variables in transpedicular screw fixation - A biomechanical study. Spine 1990;15:195-201.

33. Willet K, Hearn TC, Cuncins AV. Biomechanical testing of a new design for Schanz pedicle screws. J Spinal Disord 1993;7:375-80.

34. Wittenberg RH, Lee KS, Shea M, White AA, Hayes WC. Effect of screw diameter, insertion, technique, and bone cement augmentation of pedicle screw fixation strength. Clin Orthop 1993;296:278-87.

35. Krag MH, Beynnon BD, Pope MH, Frymover JW, Haugh LD, Weaver DL. A internal fixation for posterior application to short segments of the thoracic, lumbar, or lumosacral spine. Clin Orthop 1986;203:75-98.

36 . Misenhimer GR, Peek RD, Wiltse LL, Rothman SLG, Widell EH Jr. Anatomic analysis of pedicle cortical and cancellous diameter as related to screw size. Spine 1989;14:367-72.

37. Pfeifer BA, Krag MH, Johnson C. Repair of failed transpedicle screw fixation. A biomechanical study comparing polymethylmethacrylate, milled bone, and matchstick bone reconstruction. Spine 1994;19:350-3.

38. Zindrick MR, Wiltse LL, Widell EH, Thomas JC, Holland WR, Field BT, et al A biomechanical study of intrapedicular screw fixation in the lumosacral spine. Clin Orthop 1986;203:99-112.

39. Krag MH. Biomechanies of transpedicle spine fixation. The lumbar spine. $2^{\text {nd }}$ edition. Philadelphia: Saunders; 1996: p. 1177-203

40. McLain RF, Sparling E, Benson DR. Early failure of short segment pedicle instrumentation for thoraco-Lumbar fracture. J Bone Surg 1993;75-A:162-7.

41. Halvorson TL, Kelley LA, Thomas KA, Whitecloud TS, Cook SD. Effects of bone mineral density on pedicle screw fixation. Spine 1994;19:2415-20.

42. Chiba M, Mclain RF, Yerby SA, Moseley TA, Smith TS, Benson Dr: Short-segment pedicle instrumentation. Biomechanical analysis of supplemental hook fixation. Spine 1996;21:288-94.

43. Ferguson RL, Tencer AF, Woodard P, Allen BL. Biomechanical comparison of spinal fracture models and the stabilizing effects of posterior instrumentations. Spine 1988;13:453-60. 
44. Graziano GP. Cotrel-Dubousset hook and screw combination for spine fractures. J Spinal Disorders 1993;6:380-5.

45. Kotani Y, Cunningham BW, Cappuccino A, Kaneda K, McAfee PC. The role of spinal instrumentation in augmenting lumbar posterolateral fusion. Spine $1996 ; 21: 278-87$.

46. Yoganandan N, Pintar F, Maiman DJ, Reinartz J, Sances A, Larson S.J, Cusick JF. Kinematies of the lumbar spine following pedicle screw plate fixation. Spine $1993 ; 18: 504-12$.

47. Gwon JK, Chen J, Lim TH, Han JS, Weinstein JN, Goel VK. In vitro comparative biomechanical analysis of transpedicular screw instrumentations in the lumber region of the human spine. J Spinal Discord 1991;4:437-43.

48. Ashman RB, Galpin RD, Corin JD, Johnston CE. Biomechanical analysis of pedicle screw instrumentation systems in a corpectomy model. Spine 1989;14:1398-405.

49. Chang KW, Dewei Z, McAfee PC, Warden KE, Farey ID, Gurr KR. A comparative biomechanical study of spinal fixation using combination spinal rod-plate and transpedicular screw fixation system. J Spinal Disord 1988;1:257-66.

50. Goel VK, Nye TA, Clark CR, Nishiyama K, Weinstein .JN. A technique to evaluate an internal spine device by use of the Selspot system, an application to Luque closed loop. Spine 1987;12:150-8.

51. Goel VK, Weinstein J. Biomechanies of the Spine: Clinical and Surgical Perspective. CRC Press Inc. Boca Raton: Florida; 1990.

52. Gurr KR, McAfee PC, Shih CM. Biomechanical analysis of anterior and posterior instrumentation systems after corpectomy. J Bone Joint Surg 1988;70A:118291.

53. Lim TH. Design of a spinal fixation device and its evaluation: an analytical and an experimental approach. Ph.D. Dissertation, University of Iowa, Iowa City, IA, 1990

54. Panjabi MM, Abumi K, Duranceau J, Crisco JJ. Biomechanical evaluation of spinal fixation devices - Part II stability provided by eight internal fixation devices. Spine 1988;13:1135-40.

55. Panjabi MM. Biomechanical evaluation of spinal fixation devices. Part I: A conceptual framework. Spine 1988;13:1129-34.

56. Crock HV. Design and applications of a new device for internal fixation of bones. Med J Aus 1975;1:510-2

57. Pintar FA, Maiman DJ, Yoganandan N, Droese KW, Hollowell JP, Woodard E. Rotational stability of spinal pedicle screw/rod system. J Spinal Discoed 1995;8:4955

58. Goel VK, Lim TH, Gilbertson LG, Weinstein JN. Clinically relevant finite element models of ligamentous lumbar motion segment. Seminar Spine Surg 1993;5:29-41.

59. Penta M, Sandhu A, Fraser RD. magnetic resonance imaging assessment of disc degradation 10 years after anterior lumbar interbody fusion. Spine 1995;20:7437.

60. Boden SD, Schimandle JH. Biological enhancement of spinal fusion. Spine 1995;20:113S-23S.

61. Boden SD, Sumner Dr. Biological factors affecting spinal fusion and bone regeneration. Spine 1995;20:102S-12S

62. Kong WZ, Goel VK, Gilbertson LG, Weinstein .JN. Effects of muscle dysfunction on lumbar spine mechanies - A finite element study based on a two motion segments model. Spine (Accepted)

63. Harris KG, Lee SJ, Goel VK, Clark CR. Spinal motion following cervical fusion: In vivo assessment with roentgen stereophotogrammetry. Spine 1994;19:2336-42.

64. Johnsson R, Selvik G, Stromqvist B, Sunden G. Mobility of the lower lumbar spine after posterolateral fusion determined by roentgen stereophotogrammetric analysis. Spine 1990;15:347-50.
65. Johnsson R, Stromqvist B, Axelsson P, Selvik G. Influence of spinal immobilization on consolidation of posterolateral lumbosacral fusion: A roentgen stereophotogrammetric and radiographic analysis. Spine 1992;17:16-21.

66. Lee S, Harris K, Nassif.J, Goel V, Clark C. In vivo kinematies of the cervical spine. Part I: Development of a roentgen stereophotogrammetric technique using metallic markers and assessment of its accuracy. J Spinal Discord 1993;6:522-34.

67. Olsson TH, Selvik G, Willner S. Mobility in Lumbosacral spine after fusion studies with aid of roentgen stereophotogrammetry. Clin Orthop 1977;129:181-90.

68. Goel VK, Pope MH. Biomechanies of fusion and stabilization. Spine 1995;20:85S99S.

69. Bogdanffy GM, Ohnmeiss DD, Guyer RD. Early changes in bone mineral density above a combined anteroposterior L4-S1 lumbar spinal fusion - a clinical investigation. Spine 1995;20:1674-8.

70. Farcy JP, Rawlins BA, Glassman SD. Technique and results of fixation to the sacrum with illiosacral screws. Spine 1992;17:S190-5.

71. Farey ID, McAfee PC, Gurr KR, Randolph MA. Quantitative histologie study of the influence of spinal instrumentation on lumbar fusion: a canine model. J Orthop Res 1989;7:709-22.

72. Fraser RD: Interbody, posterior and combined lumbar fusions. Spine $1995 ; 20: 167 \mathrm{~S}-77 \mathrm{~S}$.

73. Goel VK, Lim TH, Gwon J. Chen JY, Winterbottom JM, Park JB, et al. Effect of rigidity of an internal fixation device - A comprehensive biomechanical investigation. Spine 1991:16:S155-61.

74. Gurr KR, McAfee PC, Warden KE, Shih CM. Roentgenographic and biomechanical analysis of lumbar fusions: a canine model. J Orthop Res 1989; 7:838-48.

75. Heggeness MH, Esses SI. Translaminar facet joint screw fixation for lumbar and lumosacral fusion - A clinical and biomechanical study. Spine 1991;16:S266-9.

76. Johnston CE, Ashman RB, Baird AM, Allard RN. Effect of Spinal Construct Stiffness on Early Fusion Mass Incorporation: Experimental Study. Spine 1990;15:908-12.

77. Lipscomb HJ, Grubb SA, Talmage RV. Spinal bone density following spinal fusion. Spine 1989;14:477.

78. MacMillan M, Cooper R, Haid R. Lumbar and Lumosacral Fusions Using CotrelDubousset Pedicle Screws and Rods. Spine 1994;19:430-4.

79. McAfee PC, Farey ID, Sutterlin CE, Gurr KR, Warden KE, Cunningham BW. Device-related osteoporosis with spinal instrumentation. Spine 1989;14:919-26.

80. McAfee PC, Lubicky .JP, Werner FW. The use of segmental spinal instrumentation to preserve longitudinal spinal growth - An experimental study. J Bone Joint Surg 1983;65A:935-42

81. McAfee PC, Werner W, Glisson RR. A Biomechanical analysis of spinal instrumentation systems in thoracolumbar fractures - a comparison of traditional Harrington distraction instrumentation with segmental spinal instrumentation. Spine 1985;10:204-17.

82. Nasca RJ, Lemons JE, Walker J, Batson S. Multiaxis cyclic biomechanical testing of Harrington, Luque, and Drummond implants. Spine 1990;15:15-20.

83. Pfeifer M, Hoffman HE, Gilbertson LG, Clausen .J, Goel VK, Griss P. Biomechanical testing of a new variable rigidity pedicle screw implant system. American Society of Mechanical Engineers, IMECE-WAM: Chicago, Ill; 1994.

84. Yahiro MA. Comprehensive literature review. Pedicle screw fixation devices. Spine 1994;19:S2274-8

85. Yuan HA, Garfin SR, Dickman CA, Mardjetko SM. A Historical Cohort Study of Pedicle Screw Fixation in Thoracic, Lumbar, and Sacral Spinal Fusions. Spine 1994;19:S2279-96. 